\title{
Influence of cimetidine on pharmacokinetics of propranolol
}

\author{
A M HEAGERTY, M A DONOVAN, C M CASTLEDEN, J F POHL, L PATEL, A HEDGES
}

\begin{abstract}
Whole-blood propranolol concentrations were estimated for 12 hours after a single $80 \mathrm{mg}$ oral dose was given in six patients taking cimetidine and two weeks after they had stopped the drug. Mean blood propranolol concentrations were higher throughout the sampling period when the patients were taking cimetidine than when they were not, and the difference was statistically significant between one and four hours $(p<0.05)$. The mean relative bioavailability of propranolol, measured as the area under the concentration time curve, was significantly higher when the patients were taking cimetidine $(p<$ $0.025)$. The mean increase in bioavailability was 136.5 $57.6 \%$, and the results were consistent in each subject.

It is concluded from these results that cimetidine reduces the hepatic first-pass extraction of propranolol.
\end{abstract}

\section{Introduction}

The histamine $\mathrm{H}_{2}$-receptor antagonist cimetidine is widely used in the treatment of peptic ulcer. It prolongs the prothrombin time in patients receiving oral anticoagulants and decreases the elimination of antipyrine ${ }^{1}$ and benzodiazepines. ${ }^{2}{ }^{3}$ These effects are probably due to inhibition of oxidative drug-metabolising enzymes in the liver. ${ }^{4}$ Drugs having this effect not only lengthen the half life of drugs with low hepatic extraction ratios but also decrease the first-pass extraction of drugs with high extraction ratios. ${ }^{5}$ Thus cimetidine may increase

Department of Medicine, University of Leicester, Leicester LE2 7LX A $M$ HEAGERTY, MB, MRCP, medical registrar

$M$ A DONOVAN, $M B, M R C P$, medical registrar

C M CASTLEDEN, MD, MRCS, senior lecturer in geriatric medicine

J F POHL, MB, FRCP, senior lecturer in medicine

Department of Clinical Pharmacology, St Bartholomew's Hospital, London EC1A 7BE

L PATEL, BSC, research assistant

A HEDGES, BSC, PHD, research fellow the bioavailability of drugs that undergo major extraction on first pass through the liver after absorption from the gastrontestinal tract.

To test this hypothesis we undertook the present study. We chose to study the effect of cimetidine on propranolol since propranolol undergoes considerable first-pass extraction and is often used in clinical practice.

\section{Patients and methods}

We studied six patients (average age 56 years, range 22-70 years), of whom four were men. Each had been taking cimetidine for peptic ulceration in a dose of $200 \mathrm{mg}$ by mouth three times daily and $400 \mathrm{mg}$ at night for at least two weeks before the study. Local ethical committee approval was obtained and each patient gave informed consent. All were non-smokers and had no evidence of respiratory, cardiovascular, renal, or thyroid disease. No other drug was taken apart from cimetidine.

The patients were given a test dose of $10 \mathrm{mg}$ propranolol by mouth, and no ill effects were recorded. After an overnight fast $80 \mathrm{mg}$ propranolol was given by mouth and $5 \mathrm{ml}$ blood samples were taken from an antecubital vein at $0,30,60,90,120,240,260$, 480 , and 720 minutes for estimation of the blood propranolol concentration. At 0 minutes $10 \mathrm{ml}$ of venous blood was also taken into a lithium heparin tube for measurement of plasma cimetidine concentration to ascertain compliance. All samples were stored at $-20^{\circ} \mathrm{C}$

At least two weeks after the patients had stopped taking cimetidine the study was repeated using the same dose of propranolol and the same blood sampling method.

Estimation of blood propranolol concentrations-Whole blood was used for measurement of propranolol concentrations by a fluorometric assay. ${ }^{6}$ Duplicate $1 \mathrm{ml}$ samples were alkalised with $0.5 \mathrm{ml}$ of normal sodium hydroxide and extracted into $6 \mathrm{ml}$ of $1.5 \%$ amyl alcohol in $n$-heptane. After centrifugation at $1000 \mathrm{~g}$ for five minutes $5 \mathrm{ml}$ of the upper heptane layer was added to a tube containing $1.5 \mathrm{ml}$ of $0.01 \mathrm{~N}$ hydrochloric acid. The resulting solution was shaken for 10 minutes and centrifuged for five minutes to extract the drug into the acid. The fluorescence of the acid phase was measured in an AmincoBowman spectrophotometer with the maximum excitation set at $295 \mathrm{~nm}$ and the maximum emission wavelength at $350 \mathrm{~nm}$.

Estimation of plasma cimetidine concentrations-Assay of cimetidine concentrations was carried out on plasma by the biochemistry department of Smith, Kline and French Research Ltd (Welwyn Garden City, Herts). The method used was high-pressure liquid 
chromatography using ultraviolet detection, ${ }^{7}$ and the assay was specific for cimetidine.

Pharmacokinetic analysis-The blood concentration time curves for propranolol during and after treatment with cimetidine were submitted to pharmacokinetic analysis by a Hewlett-Packard computer. The total area under the blood concentration time curve was calculated by means of the trapezoidal rule formula, ${ }^{8}$ using the data points from 0 to 720 minutes. With this method the plasma concentration time curve is described by a function that depicts the curve as a series of straight lines, thereby enabling the area under the curve to be divided into several trapezoids. This area was used as a measure of relative bioavailability of the drug.

Statistical analysis-The data obtained during and after treatment with cimetidine were compared by means of Student's $t$ test for paired data.

\section{Results}

Blood propranolol concentration-Mean blood propranolol concentrations were significantly higher between one and four hours when patients were taking cimetidine than when they were not (figure). The mean peak concentration during treatment with

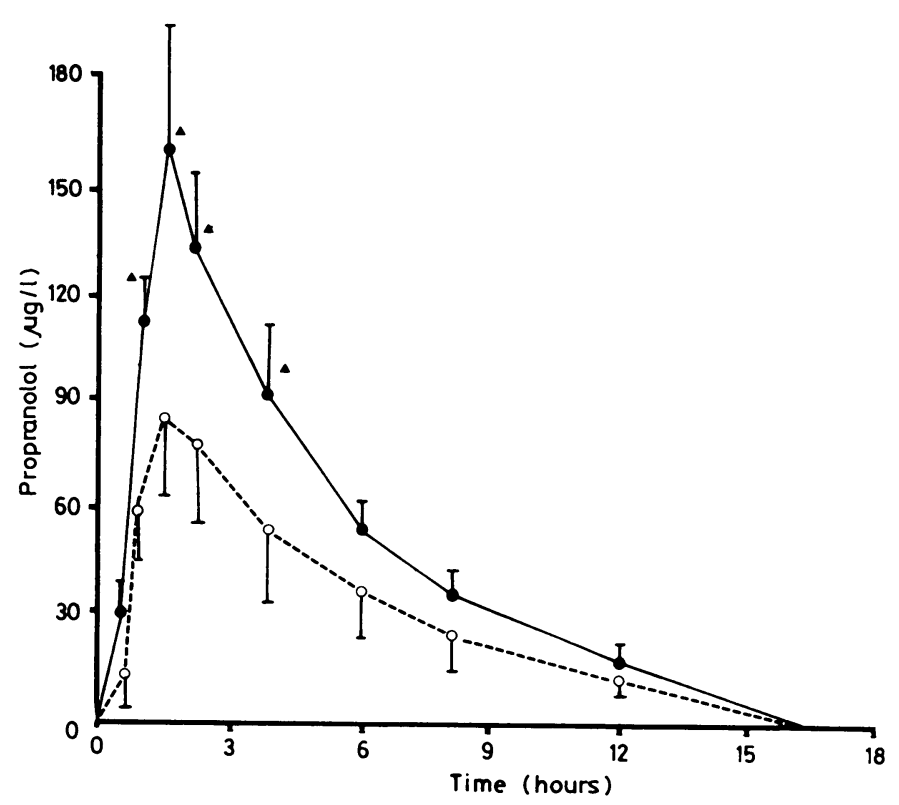

Mean \pm SEM blood propranolol concentrations while patients were (- and were not ( $O$ - - - O) taking cimetidine.

$\Delta$ Significance of difference in concentration $\mathrm{p}<0.05$.

cimetidine $(172 \cdot 5 \pm 36 \cdot 7 \mu \mathrm{g} / \mathrm{l})$ was almost twice that when patients were not taking this drug $(95.9 \pm 25.4 \mu \mathrm{g} / \mathrm{l})(\mathrm{p}<0.025)$; the mean peak concentration occurred slightly earlier during treatment with cimetidine (mean $1 \cdot 4 \pm 0.2$ hours $v 1 \cdot 5 \pm 0 \cdot 2$ hours), but this difference was not significant.

Bioavailability of propranolol-The mean area under the blood concentration time curve was significantly higher when the patients were taking cimetidine than when they were not $(727 \pm 125 \cdot 6 \mathrm{v}$ $450 \cdot 2 \pm 167 \cdot 9 \mu \mathrm{g} / 1 \mathrm{~min} ; \mathrm{p}<0 \cdot 05)$.

Plasma cimetidine concentration-Plasma cimetidine concentrations confirmed compliance in all subjects. One patient had a high concentration of cimetidine because he had taken his morning dose of the drug on the day of study. There was no correlation between plasma cimetidine concentrations and the increase in propranolol concentration during treatment with cimetidine.

\section{Discussion}

The relative bioavailability (area under the curve) of drugs with high hepatic extraction ratios is inversely proportional to the intrinsic clearance of hepatic metabolism. ${ }^{5}$ Thus the amount of such drugs removed on first pass through the liver after absorption from the gastrointestinal tract depends on liver function, which may be altered by disease, aging, and drugs. Since propranolol is avidly extracted by the liver the higher plasma concentrations and bioavailability found in the present study when the patients were taking cimetidine indicate that cimetidine decreases the first-pass extraction of propranolol. The results were consistent in each subject, indicating that they were not spurious. Moreover, propranolol accumulates during continued administration, which has been attributed to continued saturation of high-affinity extraction. ${ }^{9}$ Thus we would expect an even greater effect if the study was repeated in the steady state.

To confirm fully the increase in bioavailability a study looking at the effects of cimetidine on intravenously administered propranolol would have to be undertaken; this was not possible in our patients.

Cimetidine reduces the elimination of drugs with low extraction ratios such as the benzodiazepines antipyrine and warfarin, probably by inhibiting oxidative drug-metabolising enzymes in the liver. The effect of cimetidine on the bioavailability of propranolol is probably due to the same mechanism. Alternatively, the present results might be explained by cimetidine increasing the absorption of propranolol. The time to peak concentration, however, was not altered, and absorption of propranolol from the gastrointestinal tract is virtually complete under normal circumstances and is not affected by varying rates of gastric emptying. ${ }^{10}$

The pharmacokinetics of propranolol are affected by smoking, ${ }^{11}$ liver disease, ${ }^{12}$ chronic renal failure, ${ }^{13}$ and thyroid disease. ${ }^{14}$ All these conditions, however, were excluded in the patients studied. Blood was collected in plastic syringes, which do not alter propranolol concentration, ${ }^{15}$ and indwelling cannulae were avoided because heparin displaces propranolol from plasma binding sites. ${ }^{16}$ Cimetidine is unlikely to displace propranolol from protein binding sites as it is only $20 \%$ bound. Cimetidine did not fluoresce or interfere with the assay of propranolol, which is specific for that drug and does not measure its metabolites. ${ }^{6}$ Plasma half lives of propranolol were not calculated from our data because the drug was given by mouth and there were insufficient points to permit extrapolation of the linear section of the $\log$ blood concentration time curve.

Most adverse reactions to propranolol occur in the first four hours after the start of treatment, when the major change in sympathetic tone occurs. Since the pharmacological affect is also related to the plasma concentration extreme care needs to be taken in starting propranolol in patients already taking cimetidine. This may also be true for other drugs that undergo considerable first-pass extraction as they are probably similarly affected by cimetidine.

We thank Smith, Kline and French for measuring plasma cimetidine concentrations, submitting the propranolol data to computer analysis, and providing a grant to support the project.

\section{References}

${ }^{1}$ Serlin MJ, Sibeon RG, Mossman S, et al. Cimetidine: interaction with oral anticoagulants in man. Lancet 1979 ;ii:317-9.

2 Klotz U, Reimann I. Delayed clearance of diazepam due to cimetidine. $N$ Engl f Med 1980;302:1012-4.

${ }^{3}$ Desmond PV, Patwardhan RV, Schenker S, Speeg KV Jr. Cimetidine impairs elimination of chlordiazepoxide (Librium) in man. Ann Intern Med 1980;93:266-8.

4 Puurunen J, Pelkonen O. Cimetidine inhibits microsomal drug metabolism in the rat. Eur $\mathcal{F}$ Pharmacol 1979;55:335-6.

"Wilkinson GR, Shand DG. A physiological approach to hepatic drug clearance. Clin Pharmacol Ther 1975;18:377-90.

${ }^{6}$ Shand DG, Nuckolls EM, Oates JA. Plasma propranolol levels in adults with observations in four children. Clin Pharmacol Ther 1970;11: 112-20.

${ }^{7}$ Lee RM, Osborne PM. High-pressure liquid chromatographic determination of cimetidine sulphoxide in human blood and urine. $\mathcal{F}$ Chromatogr 1978;146:354-60. 
${ }^{8}$ Saunders L, Natunen T. A four parameter model for oral drug absorption. 7 Pharm Pharmacol 1976;28:572-9.

${ }^{9}$ Evans GH, Shand DG. Disposition of propranolol. V. Drug accumulation and steady-state concentrations during chronic oral administration in man. Clin Pharmacol Ther 1973;14:487-93.

${ }^{10}$ Castleden CM, George CF, Short MD. Contribution of individual differences in gastric emptying to variability in plasma propranolol concentrations. Br f Clin Pharmacol 1978;5:121-2.

11 Vestal RE, Wood AJJ, Branch RA, Shand DG, Wilkinson GR. Effects of age and cigarette smoking on propranolol disposition. Clin Pharmacol Ther $1979 ; 26: 8-15$.

12 Wood AJJ, Kornhauser DM, Wilkinson GR, Shand DG, Branch RA. The influence of cirrhosis on steady-state blood concentrations of unbound propranolol after oral administration. Clin Pharmacokinet $1978 ; 3: 478-87$
${ }^{13}$ Lowenthal DT, Briggs WA, Gibson TP, Nelson H, Cirksena WJ. Pharmacokinetics of oral propranolol in chronic renal disease. Clin Pharmacol Ther $1974 ; 16: 761-9$.

${ }^{14}$ Feely J, Stevenson IH. The effect of age and hyperthyroidism on plasma propranolol steady state concentration. Br f Clin Pharmacol 1978;6: $446 \mathrm{P}$.

${ }^{15}$ Cotham RH, Shand DG. Spuriously low plasma propranolol concentrations resulting from blood collection methods. Clin Pharmacol Ther 1975;18:535-8.

16 Wood M, Shand DG, Wood AJJ. Altered drug binding due to the use of indwelling heparinized cannulas (heparin lock) for sampling. Clin Pharmacol Ther 1979;25:103-7.

(Accepted 24 April 1981)

\title{
Double-blind trial of oral 1,25 -dihydroxy vitamin $D_{3}$ versus placebo in asymptomatic hyperparathyroidism in patients receiving maintenance haemodialysis
}

\author{
D E MEMMOS, J B EASTWOOD, L B TALNER, P E GOWER, J R CURTIS, M E PHILLIPS, \\ G D CARTER, J ALAGHBAND-ZADEH, A P ROBERTS, H E DE WARDENER
}

\begin{abstract}
Fifty-seven patients who had been receiving maintenance haemodialysis for a mean of 4.6 years were given 0.25-0.5 $\mu$ oral 1,25-dihydroxy $\left(1,25-(\mathrm{OH})_{2}\right)$ vitamin $D_{3}$ or a placebo in a double-blind manner for one to two years. In patients with normal radiographs (mean plasma parathyroid hormone concentration $205 \mu \mathrm{lEq} / \mathrm{ml}$ ) 1,25$(\mathrm{OH})_{2}$ vitamin $D_{3}$ prevented the development of the radiological appearances of hyperparathyroidism. In patients with abnormal radiographs (mean plasma parathyroid concentration $709 \mu \mathrm{lEq} / \mathrm{ml}) \quad 1,25-(\mathrm{OH})_{2}$ vitamin $\mathrm{D}_{3}$ arrested or reversed the radiological changes of hyperparathyroidism. Nevertheless, the response was slow and the concentration of the hormone remained considerably raised (mean $445 \mu \mathrm{lEq} / \mathrm{ml}$ ).

It is concluded from these results that giving 1,25-(OH) vitamin $D_{3}$ to patients receiving maintenance haemodialysis who have normal hand radiographs or minimal erosions is beneficial. In patients with more advanced hyperparathyroidism parathyroidectomy should be considered unless there is a rapid response.
\end{abstract}

\footnotetext{
Departments of Medicine and Clinical Pathology, Charing Cross Hospital Medical School, London W6 8RF

D E MEMMOS, MD, British Council fellow

J B EASTWOOD, MD, MRCP, lecturer in medicine (present appointment: consultant physician, St George's Hospital, London SW 17)

P E GOWER, MD, FRCP, consultant nephrologist

J R CURTIS, MD, FRCP, senior lecturer in medicine

$M$ E PHILLIPS, MD, MRCP, lecturer in medicine

G D CARTER, MSC, principal biochemist

J ALAGHBAND-ZADEH, PHD, MRCPATH, senior lecturer in chemical pathology

A P ROBERTS, PHD, lecturer in microbiology

H E DE WARDENER, MD, FRCP, professor of medicine
}

Department of Radiology, University of California, San Diego, USA L B TALNER, MD, professor of radiology

\section{Introduction}

By the time patients have been receiving dialysis for five years $15 \%$ have disabling bone disease, ${ }^{1}$ much of which is due to hyperparathyroidism. At Charing Cross Hospital symptomatic bone disease is uncommon, but in 1976, before the introduction of 1,25-dihydroxy $\left(1,25-(\mathrm{OH})_{2}\right)$ vitamin $\mathrm{D}_{3}, 16$ out of 33 patients who had been receiving dialysis for four years or more showed radiological subperiosteal erosions in the fingers and six had undergone parathyroidectomy. Up to this time oral administration of calcium salts, control of dialysate calcium concentration, and control of plasma phosphate concentration by dietary means or administration of aluminium hydroxide had been used to try to prevent and reverse hyperparathyroidism.

After the introduction of $1,25-(\mathrm{OH})_{2}$ vitamin $D_{3}$ several favourable reports appeared based on short-term studies. ${ }^{2-4} \mathrm{We}$ report the results of a controlled clinical trial comparing the effect of administering for one to two years small doses of oral $1,25-(\mathrm{OH})_{2}$ vitamin $\mathrm{D}_{3}$ or an identical placebo capsule to patients receiving dialysis.

\section{Methods \\ PATIENTS AND DESIGN OF STUDY}

The study was started in April 1977, when 127 patients were receiving maintenance haemodialysis. Of these, 106 were receiving home dialysis; 64 entered the trial. The patients were dialysed for 10 hours twice a week using a single-pass system with Kiil dialysers and Cuprophan membranes (PT150). Patients who had plasma calcium concentrations of over $3 \mathrm{mmol} / 1(12 \mathrm{mg} / 100 \mathrm{ml})$ or symptomatic hyperparathyroidism, had already received $1,25-(\mathrm{OH})_{2}$ vitamin $\mathrm{D}_{3}$ or $1 \alpha-\mathrm{OH}$ vitamin $\mathrm{D}_{3}$, or had had a parathyroidectomy were excluded from the trial. Similarly, because of the tendency of patients to show transient improvement in radiological hyperparathyroidism when they first receive maintenance haemodialysis ${ }^{5}$ patients were not entered into the trial until they had been receiving dialysis for at least a year. Then one of us (APR), who had no contact with the patients, allocated them into two groups to receive either $0.5 \mu \mathrm{g} 1,25-(\mathrm{OH})_{2}$ vitamin $\mathrm{D}_{3}$ or an identical placebo capsule.

The patients were seen every month for three months and then at three-monthly intervals. At each visit (two to eight hours before 